\title{
FTIR spectroelectrochemistry combined with a light-induced difference technique: Application to the iron-quinone electron acceptor in photosystem II
}

\author{
Yuki Kato* and Takumi Noguchi \\ Division of Material Science, Graduate School of Science, Nagoya University, Furo-cho, Chikusa-ku, \\ Nagoya 464-8602, Japan \\ E-mails: yuki.kato@bio.phys.nagoya-u.ac.jp,tnoguchi@bio.phys.nagoya-u.ac.jp
}

\begin{abstract}
Photosystem II (PSII) in plants and cyanobacteria performs light-driven water oxidation to obtain electrons necessary for $\mathrm{CO}_{2}$ fixation. In PSII, a series of electron transfer reactions take place from the $\mathrm{Mn}_{4} \mathrm{CaO}_{5}$ cluster, the catalytic site of water oxidation, to a plastoquinone molecule via several redox cofactors. Light-induced Fourier transform infrared (FTIR) difference spectroscopy has been extensively used to investigate the structures and reactions of the redox cofactors in PSII. Recently, FTIR spectroelectrochemistry combined with the light-induced difference technique was applied to study the mechanism of electrontransfer regulation in PSII involving the quinone electron acceptors, $\mathrm{Q}_{\mathrm{A}}$ and $\mathrm{Q}_{\mathrm{B}}$, and the non-heme iron that bridges them. In this mini-review, this combined FTIR method is introduced, and obtained results about the redox reactions of the non-heme iron and $\mathrm{Q}_{\mathrm{B}}$, involving the long-range interaction of the $\mathrm{Mn}_{4} \mathrm{CaO}_{5}$ cluster with the electron-acceptor side, are summarized.
\end{abstract}

Keywords: Electron transfer, FTIR, photosynthesis, quinone, redox potential, spectroelectrochemistry

\section{Introduction}

Photosystem II (PSII), one of the major protein complexes that work in oxygenic photosynthesis, has a unique function of light-induced water oxidation [67]. Electrons from water are ultimately used for $\mathrm{CO}_{2}$ reduction and released protons generate a proton gradient across the thylakoid membrane to synthesize ATP. In addition, molecular oxygen, a byproduct of water oxidation, makes an oxygenic atmosphere, which is essential for sustenance of life on the earth. In photosystem II, light absorption triggers charge separation between the chlorophyll dimer (P680) and the pheophytin (Pheo) electron acceptor to produce $\mathrm{P} 680^{+} \mathrm{Pheo}^{-}$[51]. On the electron-acceptor side, an electron on $\mathrm{Pheo}^{-}$is transferred to the primary quionone electron acceptor $\left(\mathrm{Q}_{\mathrm{A}}\right)$ and then to the secondary quinone electron acceptor $\left(\mathrm{Q}_{\mathrm{B}}\right)[16,38,48]$, while on the electron donor side, the electron hole on $\mathrm{P}_{680^{+}}$is transferred to the redox-active tyrosine $\left(\mathrm{Y}_{\mathrm{Z}}\right)$ then to the $\mathrm{Mn}_{4} \mathrm{CaO}_{5}$ cluster, at which water oxidation takes place via a cycle of five intermediates called $\mathrm{S}_{i}$ states $(i=0-4)$ (Fig. 1) [23,36,52]. $\mathrm{Q}_{\mathrm{A}}$ and $\mathrm{Q}_{\mathrm{B}}$ both consist of a plastoquinone-9 (PQ) molecule and are structurally linked by a non-heme iron though His ligands (D2-His214 and D1-His215) (Fig. 1)

\footnotetext{
*Corresponding author. E-mail: yuki.kato@bio.phys.nagoya-u.ac.jp.
} 


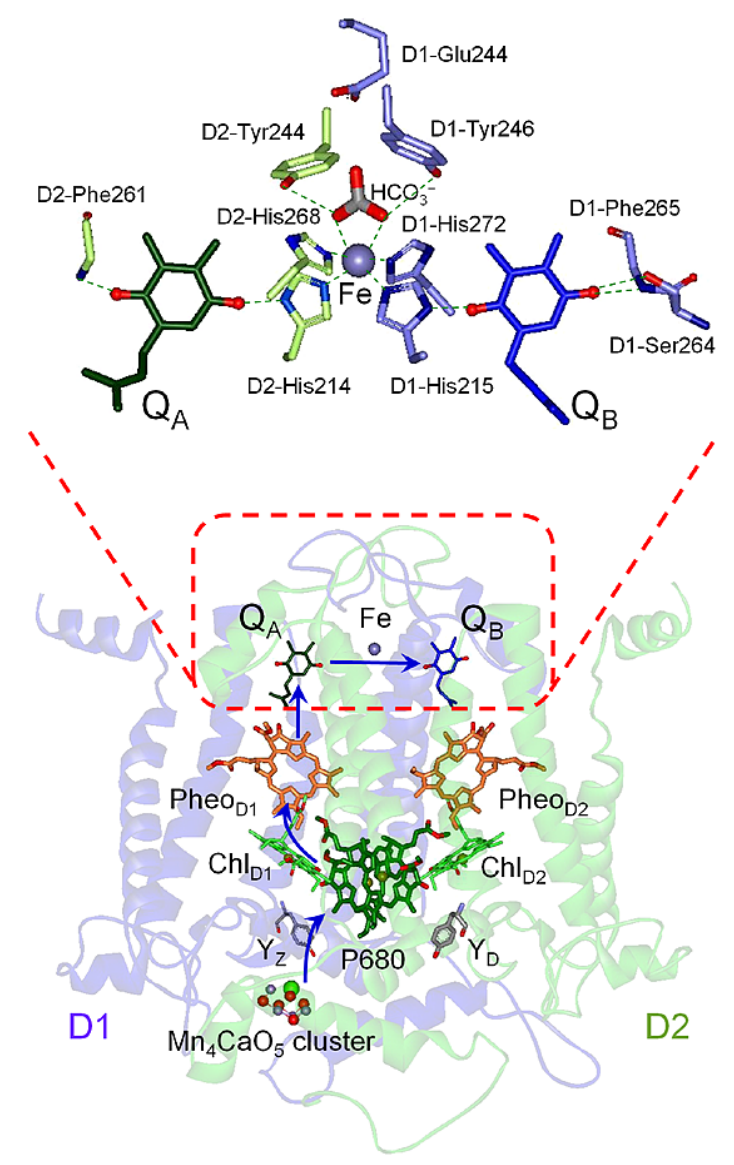

Fig. 1. Redox cofactors and the electron transfer pathway (blue arrows) in PSII. For the PSII structure, the X-ray crystallographic structure at $1.9 \AA$ resolution (PDB code: 3ARC) [63] was used. The expanded view of the electron-acceptor side shows the arrangements of $\mathrm{Q}_{\mathrm{A}}, \mathrm{Q}_{\mathrm{B}}$, and the non-heme iron with their molecular interactions.

$[18,21,63]$. In spite of the same chemical species and similar molecular interactions, $Q_{A}$ and $Q_{B}$ have rather different functions $[16,38,48]$; $\mathrm{Q}_{\mathrm{A}}$ performs only a single-electron reaction and relays an electron from $\mathrm{Pheo}^{-}$to $\mathrm{Q}_{\mathrm{B}}$, whereas $\mathrm{Q}_{\mathrm{B}}$ can be doubly reduced to become plastoquinole $\left(\mathrm{PQH}_{2}\right)$ by binding two protons and leaves the binding site of PSII.

The electron transfer reaction between $\mathrm{Q}_{A}$ and $\mathrm{Q}_{B}$ is controlled by the gap of their redox potentials $\left(\Delta E_{\mathrm{m}}\right)$. A larger $\Delta E_{\mathrm{m}}$ provides a driving force to promote an efficient forward electron transfer from $\mathrm{Q}_{\mathrm{A}}$ to $\mathrm{Q}_{\mathrm{B}}$, whereas a smaller or negative $\Delta E_{\mathrm{m}}$ promotes a backward electron transfer. The backward electron transfer, which seems non-productive in photosynthesis, also plays an important role in the photoprotection mechanism $[10,54,66]$. The $\Delta E_{\mathrm{m}}$ value between $\mathrm{Q}_{\mathrm{A}}$ and $\mathrm{Q}_{\mathrm{B}}$, however, has not been determined exactly and only indirectly predicted from kinetic and thermodynamic data $[12,15,53]$. The $E_{\mathrm{m}}$ value of $\mathrm{Q}_{\mathrm{A}}, E_{\mathrm{m}}\left(\mathrm{Q}_{\mathrm{A}}{ }^{-} / \mathrm{Q}_{\mathrm{A}}\right)$, has been extensively estimated using chemical and electrochemical titration and determined to be approximately $-100 \mathrm{mV}$ in oxygen-evolving intact PSII $[1,24,26,30,31$, 56,57]. In contrast, the $E_{\mathrm{m}}$ of $\mathrm{Q}_{\mathrm{B}}, E_{\mathrm{m}}\left(\mathrm{Q}_{\mathrm{B}}{ }^{-} / \mathrm{Q}_{\mathrm{B}}\right)$, has not been directly measured mainly because of the absence of spectroscopic methods that provide specific $\mathrm{Q}_{\mathrm{B}}$ signals. It has also been demonstrated that the $E_{\mathrm{m}}\left(\mathrm{Q}_{\mathrm{A}}{ }^{-} / \mathrm{Q}_{\mathrm{A}}\right)$ value is shifted by about $+150 \mathrm{mV}$ by depletion of the $\mathrm{Mn}_{4} \mathrm{CaO}_{5}$ cluster from PSII [1,24, $26,30,31,56,57]$. This phenomena was argued in the context of a photoprotection mechanisms, in which 
when the $\mathrm{Mn}_{4} \mathrm{CaO}_{5}$ cluster is inactivated, the electron on the quinone electron acceptors is thermally relaxed by direct recombination with $\mathrm{P} 680^{+}[10,26,32,54,65,66]$. However, the effect of inactivation of the $\mathrm{Mn}_{4} \mathrm{CaO}_{5}$ cluster on the $E_{\mathrm{m}}$ of $\mathrm{Q}_{\mathrm{B}}$ in addition to its absolute value in intact PSII was still unknown. Therefore, the full mechanism of photoprotection by regulation of the electron transfer between $\mathrm{Q}_{\mathrm{A}}$ and $\mathrm{Q}_{\mathrm{B}}$ has not been established. Another important question here is how inactivation of the $\mathrm{Mn}_{4} \mathrm{CaO}_{5}$ cluster influences the $E_{\mathrm{m}}\left(\mathrm{Q}_{\mathrm{A}}{ }^{-} / \mathrm{Q}_{\mathrm{A}}\right)$ through the long distance of about $40 \AA$ between the $\mathrm{Mn}_{4} \mathrm{CaO}_{5}$ cluster and $\mathrm{Q}_{\mathrm{A}}$. A possible hypothesis for this long-range interaction is that the structural change on the electron-donor side by $\mathrm{Mn}$ depletion is transferred to the $\mathrm{Q}_{\mathrm{B}}$ site through the transmembrane helices of the $\mathrm{D} 1$ subunit and then to the $\mathrm{Q}_{\mathrm{A}}$ site via the molecular bridge of the non-heme iron $[10,28,31]$. If this were the case, the donor-side perturbation would influence the redox properties of the non-heme iron and $\mathrm{Q}_{\mathrm{B}}$ as well as $\mathrm{Q}_{\mathrm{A}}[10]$.

Light-induced Fourier transform infrared (FTIR) difference spectroscopy has been extensively used to investigate the structures and reactions of the redox cofactors in PSII [5,11,13,14,39-43]. In this method, photoreactions are initiated by illumination of continuous-wave light or flashes from a pulse laser, and the structural changes of the cofactors and surrounding protein moieties are studied by detecting small infrared absorption changes. On the other hand, an FTIR spectroelectrochemical method has been used to investigate redox reactions of biomolecules and proteins [3,6,7,20,34,35,37]. In these studies, the redox reactions were triggered by changing the electrode potential and FTIR difference spectra were measured. Spectroelectrochemistry utilizing UV-Vis and fluorescence spectroscopies has been used to determine the $E_{\mathrm{m}}$ values of redox cofactors [17,29,56-58]. The merit of FTIR spectroelectrochemistry over such conventional methods is that it provides additional information of structural changes coupled to the redox reactions. In this mini-review, we introduce our recent approaches using FTIR spectroelectrochemistry combined with light-induced FTIR difference technique to investigate the redox and structural properties of the non-heme iron and $\mathrm{Q}_{в}[27,28]$. In particular, the $E_{\mathrm{m}}$ of $\mathrm{Q}_{\mathrm{B}}$ was directly measured for the first time using FTIR signals specific to $Q_{B}$ [27]. The results provided a clear view on the regulation mechanism of electron transfer in PSII upon inactivation of the $\mathrm{Mn}_{4} \mathrm{CaO}_{5}$ cluster and an insight into the long-range interaction between the electron donor and acceptor sides of the PSII protein complex.

\section{Instrumental setup of FTIR spectroelectrochemistry combined with light-induced FTIR difference spectroscopy}

Figure 2A shows a schematic view of an optically transparent thin-layer electrode (OTTLE) cell used in our FTIR spectroelectrochemical measurements. This cell is similar to the ones previously reported [7,37]. Because strong infrared absorption of water interferes with the bands of proteins, a very thinlayer metal mesh, for example $6 \mu \mathrm{m}$ in thickness, is used as a working electrode. When an Au working electrode is used, the surface of the electrode is modified with thiols to prevent irreversible adsorption and denaturation of proteins [62]. A commercially obtained $\mathrm{Ag} / \mathrm{AgCl} / 3 \mathrm{M} \mathrm{KCl}$ reference electrode (Cypress Systems Inc., 66-EE009; $+208 \mathrm{mV}$ vs. SHE) with a diameter of $2 \mathrm{~mm}$ and a Pt black wire as a counter electrode are arranged in the Teflon body (Fig. 2A).

Because redox cofactors located inside a protein are difficult to interact with an electrode directly, redox mediators are necessary for electrochemical measurements. Several mediators are used to cover the potential regions of target cofactors. For example, for the measurement of the non-heme iron in PSII, $\mathrm{Ru}\left(\mathrm{NH}_{3}\right)_{6} \mathrm{Cl}_{2}\left(E_{\mathrm{m}}=+51 \mathrm{mV}\right), \mathrm{K}_{3} \mathrm{Fe}(\mathrm{CN})_{6}\left(E_{\mathrm{m}}=+430 \mathrm{mV}\right)$, and ferreocenylmethyl trimetyl ammonium $\left(E_{\mathrm{m}}=+627 \mathrm{mV}\right)$ were used [28], while for $\mathrm{Q}_{\mathrm{B}}$, 1-methoxy-5-methylphanazinium 


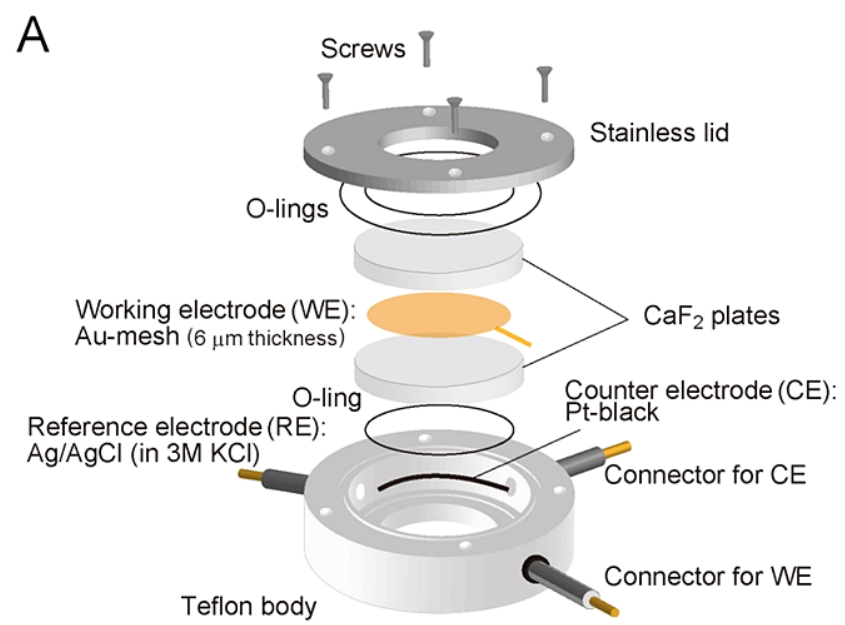

B

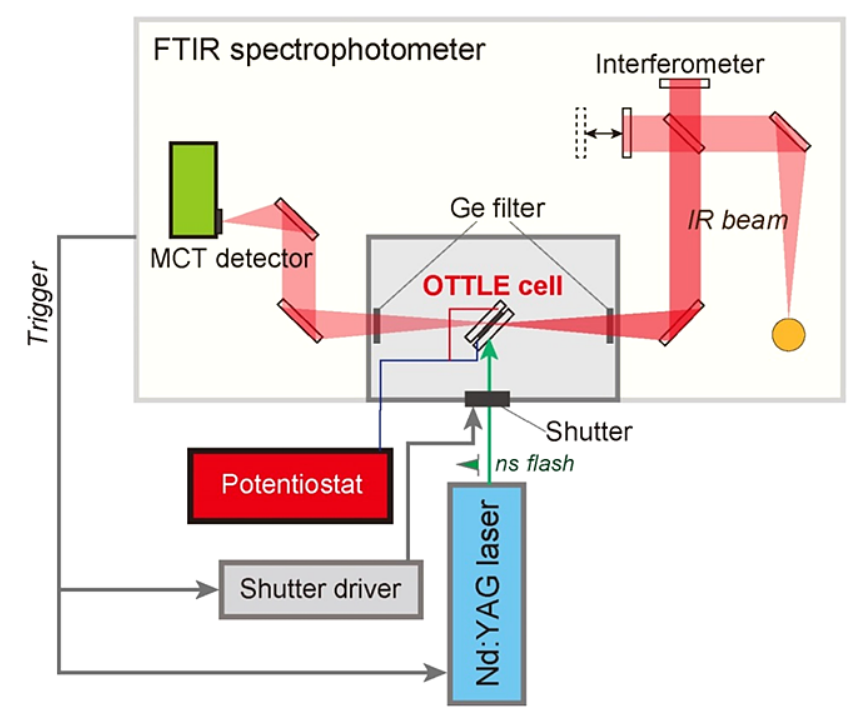

Fig. 2. (A) An optically transparent thin-layer electrode (OTTLE) cell designed for light-induced difference FTIR spectroscopy. (B) Instrumental setup for measurements of flash-induced FTIR difference spectra of a sample in an OTTLE cell, in which the potential of the working electrode is controlled by a potentiostat.

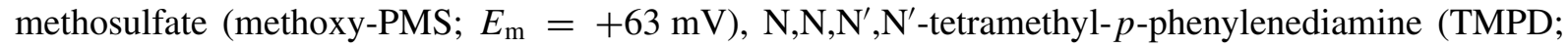
$\left.E_{\mathrm{m}}=+260 \mathrm{mV}\right)$, and $\mathrm{K}_{3} \mathrm{Fe}(\mathrm{CN})_{6}\left(E_{\mathrm{m}}=+430 \mathrm{mV}\right)$ were used [27]. A sample containing the mediators is sandwiched between a pair of $\mathrm{CaF}_{2}$ plates together with an $\mathrm{Au}$ mesh. The interspace between the $\mathrm{CaF}_{2}$ plates and the Teflon body is filled with a buffer solution containing mediators to achieve an electric contact between the working electrode and the counter and reference electrodes.

For photosensitive proteins like PSII, there is a merit to combine the spectroelectrochemistry and a light-induced difference technique for studies of redox cofactors. The $\Delta A$ values for the redox reactions of cofactors in PSII are very small, usually in the level of $10^{-5}-10^{-4}[5,11,13,14,39-43]$, and 
hence electrochemically-induced FTIR difference spectra of the redox cofactors are not easy to measure with a high quality due to baseline changes during the period in which a redox equilibrium is reached (sometimes tens of minutes). In contrast, high-quality difference spectra can be obtained by utilizing the light-induced difference method for a sample that is equilibrated at a certain redox potential controlled by a potentiostat. Using this combined FTIR method of spectroelectrochemistry and light-induced difference spectroscopy, the redox properties like $E_{\mathrm{m}}$ values and the structural changes upon redox reactions are obtained simultaneously.

For light-induced FTIR difference measurements of electrochemically controlled samples, the OTTLE cell wired with a potentiostat is set in the sample room of FTIR spectrophotometer (Fig. 2B), and light illumination is performed, for example by flashes from a Q-switched Nd:YAG laser $(532 \mathrm{~nm} ; \sim 7 \mathrm{~ns}$ width), which are synchronized to FTIR scans by triggers from the spectrophotometer [39]. The temperature of the OTTLE cell is controlled by circulating cold water in a copper holder. Details of the methodology of light-induced FTIR difference spectroscopy and application to PSII have been described in previous review articles $[5,11,13,14,39-43]$.

\section{FTIR spectroelectrochemical study on the non-heme iron}

The non-heme iron connects $\mathrm{Q}_{\mathrm{A}}$ and $\mathrm{Q}_{\mathrm{B}}$ by a molecular bridge, $\mathrm{Q}_{\mathrm{A}}$-His214(D2)-Fe-His215(D1)- $\mathrm{Q}_{\mathrm{B}}$ (Fig. 1) $[18,21,63]$. In addition to these His ligands, other two His residues, D1-His272 and D2-His268, and a bicarbonate ion function as ligands to the non-heme iron [18,21,63]. Under physiological conditions, the non-heme iron is not involved in the electron transfer reaction from $\mathrm{Q}_{\mathrm{A}}$ to $\mathrm{Q}_{B}[16,38,48]$, because of its high $E_{\mathrm{m}}$ value of about $+400 \mathrm{mV}$ at $\mathrm{pH} 7.0$ with a $\mathrm{pH}$ dependence of $-60 \mathrm{mV} / \mathrm{pH}$ $[8,25,44,49]$. However, under oxidative conditions, e.g., in the presence of ferricyanide, the non-heme iron is oxidized to $\mathrm{Fe}^{3+}$ and serves as an endogenous electron acceptor, and hence $\mathrm{Fe}^{3+}$ is re-reduced to $\mathrm{Fe}^{2+}$ by light illumination. This photoreaction allows the measurement of a light-induced FTIR difference spectrum of the non-heme iron to investigate the structures of the nearby protein moieties involving the $\mathrm{Q}_{\mathrm{B}}$ binding site $[4,22,44,60,61]$. Utilizing the light-induced $\mathrm{Fe}^{2+} / \mathrm{Fe}^{3+}$ measurement in combination with the spectroelectrochemical method, we recently studied the effects of the depletion of the $\mathrm{Mn}_{4} \mathrm{CaO}_{5}$ cluster on the redox and structural properties of the non-heme iron [28].

Figure 3 shows flash-induced FTIR difference spectra of the $\mathrm{O}_{2}$-evolving (a, black line) and Mn-depleted (c, red line) PSII membranes of spinach at $\mathrm{pH} 6.5$ measured in an electrolytic solution at $+600 \mathrm{mV}$ (vs. SHE) [28]. Bands at 1339, 1258, 1229, 1109, and $1101 \mathrm{~cm}^{-1}$, which were observed in both spectra, are typical of the $\mathrm{Fe}^{2+} / \mathrm{Fe}^{3+}$ difference signals $[4,22,44,60,61]$. The $1339(+) / 1229(-) \mathrm{cm}^{-1}$ bands were attributed to the symmetric CO stretching vibrations of the bicarbonate ligand [22], while the positive band at $1258 \mathrm{~cm}^{-1}$ and a part of the $1229 \mathrm{~cm}^{-1}$ negative band were assigned to the CO stretching vibration of a Tyr side chain (either D1-Tyr246 or D2-Tyr244) structurally coupled to the non-heme iron using $\left[4-{ }^{13} \mathrm{C}\right]$ Tyr labeling [60]. In addition, the $1109(+) / 1101(-)$ peaks were assigned to the $\mathrm{CN}$ stretching vibrations of the imidazole ring of the His ligands [4]. In the difference spectrum of intact PSII, signals were also observed at 1439, 1419, 1404 and $1365 \mathrm{~cm}^{-1}$, which arise from the transition from the dark-stable $S_{1}$ state to the $S_{2}$ state in the $\mathrm{Mn}_{4} \mathrm{CaO}_{5}$ cluster $[11,13,14,39-43]$. Indeed, a spectrum of intact PSII measured at pH 5.5 at $+430 \mathrm{mV}$, which reflects a pure $S_{2} / S_{1}$ difference without the contribution of the electron-acceptor side in PSII (Fig. 3a, green line), showed the same signals. These bands were assigned to the symmetric stretching vibrations of carboxylate groups surrounding the $\mathrm{Mn}_{4} \mathrm{CaO}_{5}$ cluster $[45,46]$. Because there are some minor peaks in the $\mathrm{S}_{2} / \mathrm{S}_{1}$ 


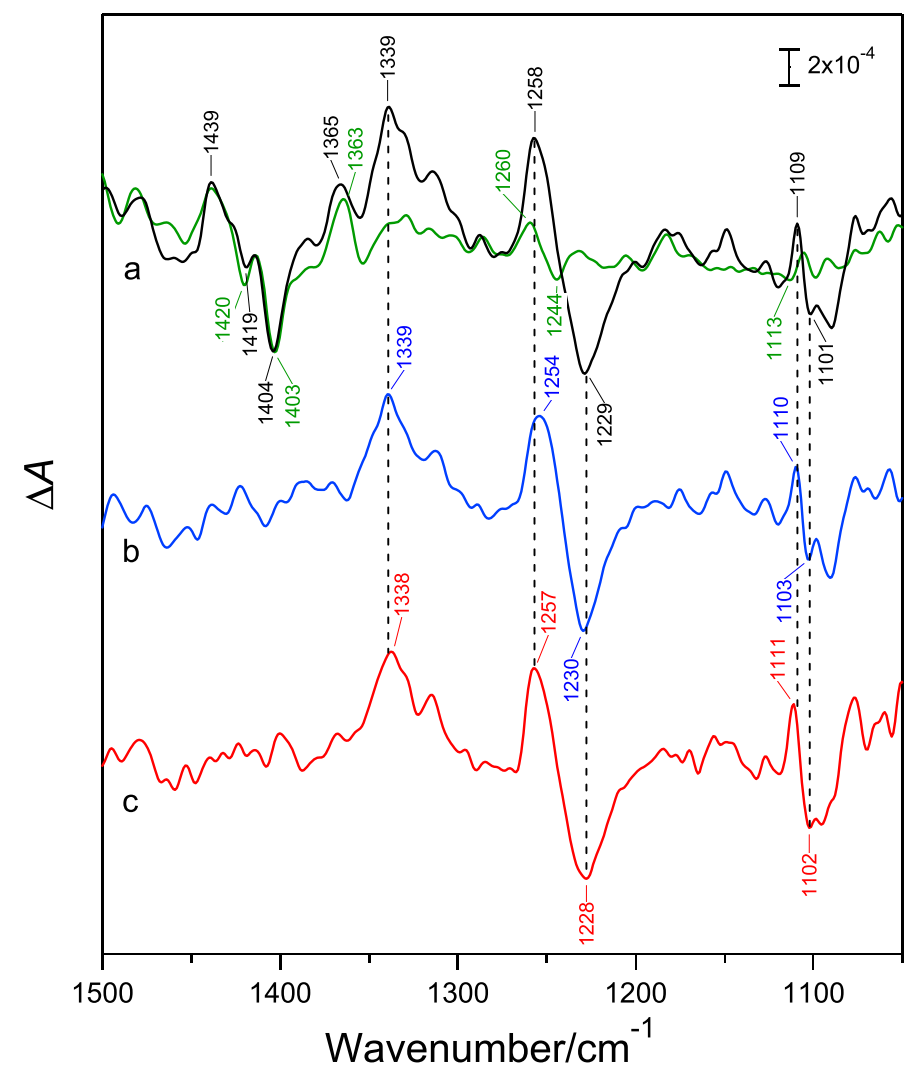

Fig. 3. (a) $\mathrm{S}_{2} \mathrm{Fe}^{2+} / \mathrm{S}_{1} \mathrm{Fe}^{3+}$ (black line) and $\mathrm{S}_{2} / \mathrm{S}_{1}$ (green line) FTIR difference spectra of the intact PSII membranes isolated from spinach. (b) $\mathrm{An} \mathrm{Fe}^{2+} / \mathrm{Fe}^{3+}$ difference spectrum of the intact PSII membranes obtained by subtraction of the $\mathrm{S}_{2} / \mathrm{S}_{1}$ spectrum from the $\mathrm{S}_{2} \mathrm{Fe}^{2+} / \mathrm{S}_{1} \mathrm{Fe}^{3+}$ spectrum in (a). (c) $\mathrm{An} \mathrm{Fe}^{2+} / \mathrm{Fe}^{3+}$ difference spectrum of the Mn-depleted PSII membranes. The $\mathrm{S}_{2} \mathrm{Fe}^{2+} / \mathrm{S}_{1} \mathrm{Fe}^{3+}$ difference spectrum of the intact PSII (a, black line) and the $\mathrm{Fe}^{2+} / \mathrm{Fe}^{3+}$ difference spectrum of the Mn-depleted PSII (c, red line) were measured at $+600 \mathrm{mV}$ at $\mathrm{pH}$ 6.5. The $\mathrm{S}_{2} / \mathrm{S}_{1}$ difference spectrum of the intact PSII (a, green line) was measured at $+430 \mathrm{mV}$ at $\mathrm{pH}$ 5.5. Reproduced from the data in Ref. [28].

difference spectrum overlapping the non-heme iron signals (e.g., bands at 1260/1244 and $1113 \mathrm{~cm}^{-1}$ ), the $S_{2} / S_{1}$ spectrum (Fig. 3a, green line) was subtracted from the $S_{2} \mathrm{Fe}^{2+} / \mathrm{S}_{1} \mathrm{Fe}^{3+}$ difference spectrum (Fig. 3a, black line) to estimate the pure contribution of $\mathrm{Fe}^{2+} / \mathrm{Fe}^{3+}$ signals in intact PSII (Fig. 3b).

From the intensities of the major signals around $1240 \mathrm{~cm}^{-1}$ in the thus-obtained $\mathrm{Fe}^{2+} / \mathrm{Fe}^{3+}$ spectra at a series of electrode potentials between +350 and $+600 \mathrm{mV}$ (Fig. 4A), the molar ratios of $\mathrm{Fe}^{3+}$ and $\mathrm{Fe}^{2+}$ were estimated and analyzed in a semilogarithmic Nernst plot (Fig. 4B) [28]. A linear relationship with slopes of 65 and $62 \mathrm{mV}$ was obtained for the intact and Mn-depleted PSII samples, respectively; These slopes are similar to the theoretical value of $56 \mathrm{mV}$ at $10^{\circ} \mathrm{C}$ (measuring temperature). The data from both PSII samples well followed the theoretical one-electron Nernstian curves (Fig. 4C), and the $E_{\mathrm{m}}\left(\mathrm{Fe}^{2+} / \mathrm{Fe}^{3+}\right)$ values were determined to be $+468 \pm 3$ and $+486 \pm 4 \mathrm{mV}$ for intact and Mn-depleted PSII samples, respectively [28]. Thus, the FTIR spectroelectrochemical measurements revealed that Mn depletion induces a relatively small shift of $E_{\mathrm{m}}\left(\mathrm{Fe}^{2+} / \mathrm{Fe}^{3+}\right)$ by $+18 \mathrm{mV}$ [28]. This value is about $\sim 8$ times smaller than the shift of $E_{\mathrm{m}}\left(\mathrm{Q}_{\mathrm{A}}{ }^{-} / \mathrm{Q}_{\mathrm{A}}\right)(\sim+150 \mathrm{mV}[1,24,26,30,31,56,57])$.

The $\mathrm{Fe}^{2+} / \mathrm{Fe}^{3+}$ difference spectra also showed some changes in the $\mathrm{COOH}$ and His $\mathrm{CN}$ regions upon Mn depletion (Fig. 5). A negative peak at $1750 \mathrm{~cm}^{-1}$ was observed in the region of the $\mathrm{C}=\mathrm{O}$ stretching 

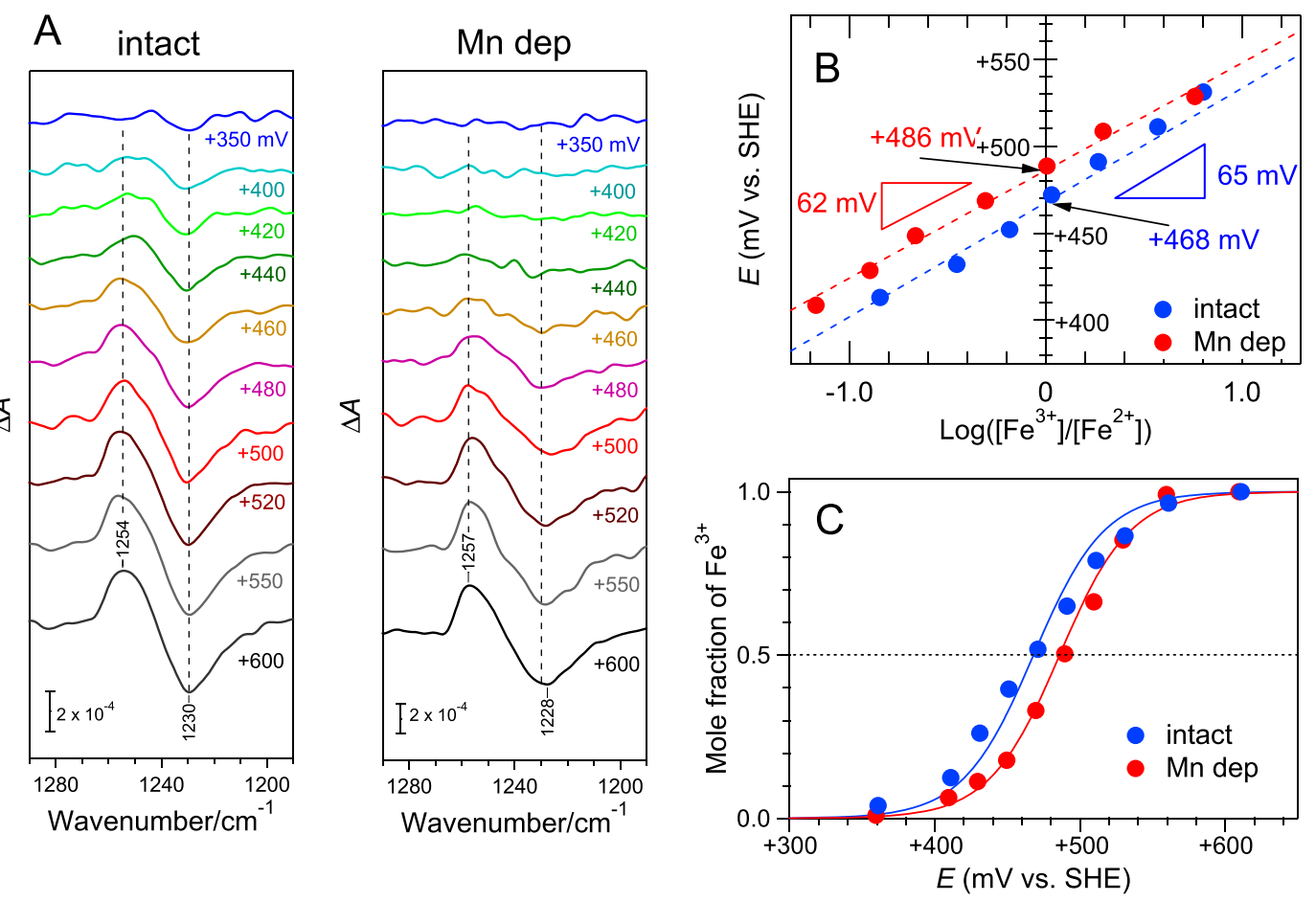

Fig. 4. (A) Major signals around $1240 \mathrm{~cm}^{-1}$ in the $\mathrm{Fe}^{2+} / \mathrm{Fe}^{3+}$ difference spectra of the intact (left panel) and Mn-depleted (right panel) PSII membranes at a series of electrode potentials. (B) Semilogarithmic Nernst plots of the redox reaction of the non-heme iron in the intact (blue circles) and Mn-depleted (red circles) PSII membranes. The regression lines (dashed line) with slopes and intercepts are also shown. (C) Plots with theoretical Nernstian curves assuming one-electron redox processes with $E_{\mathrm{m}}=+468 \mathrm{mV}$ (intact) and $+486 \mathrm{mV}$ (Mn-depleted). Reproduced from the data in Ref. [28].

\section{A}

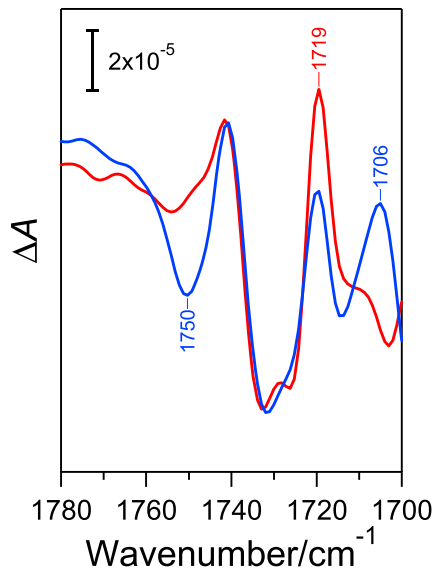

$\mathrm{B}$

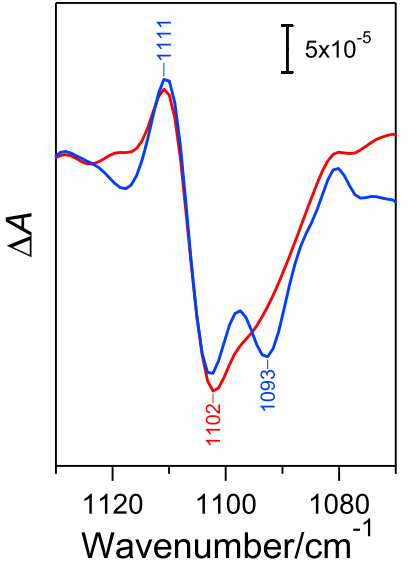

Fig. 5. $\mathrm{Fe}^{2+} / \mathrm{Fe}^{3+}$ difference spectra of the intact (blue line) and Mn-depleted (red line) PSII membranes in the regions of the $\mathrm{C}=\mathrm{O}$ stretch of $\mathrm{COOH}(\mathrm{A})$, and the $\mathrm{CN}$ stretch of His (B). Reproduced from Ref. [28]. 
vibration of $\mathrm{COOH}$ in intact PSII, whereas this band was not detected in Mn-depleted PSII (Fig. 5A). It was suggested that the $\mathrm{p} K_{\mathrm{a}}$ of a $\mathrm{COOH}$ group near the non-heme iron is upshifted upon Mn depletion [28]. One of several Glu residues (D1-Glu226, D1-Glu242, D1-Glu243, D1-Glu244, D2-Glu241, and D2-Glu242) located on the stromal side will be responsible for this band; The best candidate is D1Glu244 that is coupled to the non-heme iron through bicarbonate (Fig. 1). In the His CN region, two negative peaks were observed at 1102 and $1093 \mathrm{~cm}^{-1}$ in intact PSII, whereas the lower-frequency peak diminished upon Mn depletion (Fig. 5B). This peak has been assigned to the deprotonated anion form of His, most probably D1-His215 interacting $\mathrm{Q}_{\mathrm{B}}[4,22]$. Thus, it was suggested that the $\mathrm{p} K_{\mathrm{a}}$ of D1His215 increased upon Mn depletion. These $\mathrm{p} K_{\mathrm{a}}$ changes of the Glu and His residues as well as a small shift of $E_{\mathrm{m}}\left(\mathrm{Fe}^{2+} / \mathrm{Fe}^{3+}\right)$ by Mn depletion should results from the long-range interaction between the electron-donor and acceptor sides of PSII.

\section{FTIR spectroelectrochemical study on $Q_{B}$}

In contrast to many reports of the measurement of $E_{\mathrm{m}}$ of $\mathrm{Q}_{\mathrm{A}}[1,24,26,30,31,56,57]$, there has been no report of direct measurement of $E_{\mathrm{m}}$ of $\mathrm{Q}_{\mathrm{B}}$. The main reason for this is the difficulty in spectroscopic detection of the $\mathrm{Q}_{B}$ reaction. It is well known that fluorescence measurement is useful to monitor the redox states of $Q_{A}$ because reduction of $Q_{A}$ increases the level of fluorescence $[9,33,47,48]$. However, the fluorescence method is not applicable to the $\mathrm{Q}_{B}$ reaction. Although UV-Vis absorption and electron spin resonance have also been applied to the redox titration of $\mathrm{Q}_{\mathrm{A}}$ (summarized in [30]), these spectroscopic methods have not been used in $\mathrm{Q}_{\mathrm{B}}$ titration probably due to the similar signals of $\mathrm{Q}_{\mathrm{A}}{ }^{-}$and $\mathrm{Q}_{\mathrm{B}}{ }^{-}[19$, 50,55,64]. On the other hand, it was shown that FTIR difference spectroscopy provided signals specific to the $\mathrm{Q}_{A}$ and $\mathrm{Q}_{B}$ reactions [59]; A sharp positive peak was observed at 1721 and $1745 \mathrm{~cm}^{-1}$ in the $\mathrm{Q}_{\mathrm{A}}{ }^{-} / \mathrm{Q}_{\mathrm{A}}$ and $\mathrm{Q}_{\mathrm{B}}{ }^{-} / \mathrm{Q}_{\mathrm{B}}$ difference spectra, respectively (Fig. 6A, B). These peaks were assigned to the $13^{2}$-ester $\mathrm{C}=\mathrm{O}$ vibrations of nearby Pheo molecules $\left(\mathrm{Pheo}_{\mathrm{D} 1}\right.$ and $\mathrm{Pheo}_{\mathrm{D} 2}$ for $\mathrm{Q}_{\mathrm{A}}$ and $\mathrm{Q}_{\mathrm{B}}$, respectively; Fig. 6C), which are affected by reduction of the quinone electron acceptors [59]. The frequency of the $1721 \mathrm{~cm}^{-1}$ peak in the $\mathrm{Q}_{\mathrm{A}}^{-} / \mathrm{Q}_{\mathrm{A}}$ spectrum lower than that of the $1745 \mathrm{~cm}^{-1}$ peak in the $\mathrm{Q}_{\mathrm{B}}{ }^{-} / \mathrm{Q}_{\mathrm{B}}$ spectrum is consistent with the presence of a hydrogen bond at the $13^{2}$-ester $\mathrm{C}=\mathrm{O}$ of Pheo 1 with D1Tyr126 (Fig. 6C) [18,21,63]; The corresponding residue on the D2 side is D2-Phe125, which does not form a hydrogen bond with Pheo $\mathrm{D}_{\mathrm{D} 2}$. These peaks at 1721 and $1745 \mathrm{~cm}^{-1}$ are thus good markers to discriminate the $\mathrm{Q}_{\mathrm{A}}$ and $\mathrm{Q}_{\mathrm{B}}$ reactions.

This marker peak of $\mathrm{Q}_{B}$ at $1745 \mathrm{~cm}^{-1}$ was used to examine the redox state of $\mathrm{Q}_{B}$ at a series of the electrode potentials (Fig. 7A) [27]. Note that in this method, the $\mathrm{Q}_{\mathrm{B}}$ signal is obtained as a lightinduced change of $\mathrm{Q}_{B}$, typically one electron reduction of $\mathrm{Q}_{B}$, after reaching equilibrium of electrochemical reactions, and hence electrochemically-induced changes are not directly detected in FTIR spectra. The semilogarithmic Nernst plots of the relative intensities of this peak against the electrode potential (Fig. 7B) showed virtually linear relationships with slopes of $30 \pm 2$ and $39 \pm 1 \mathrm{mV}$ for intact and Mn-depleted PSII, respectively. These slopes are closer to $28 \mathrm{mV}$, the theoretical value of a two-electron reaction at $10^{\circ} \mathrm{C}$ (measurement temperature), than $56 \mathrm{mV}$, that of a one-electron reaction. The apparent redox potentials $\left(E_{\mathrm{m}}^{\mathrm{app}}\right)$ were obtained from the intercepts of the plots to be +155 and $+132 \mathrm{mV}$ for intact and Mn-depleted PSII, respectively (Fig. 7B). The data closer to a two-electron reaction indicates that the redox potential of the second reduction of $\mathrm{Q}_{\mathrm{B}}, E_{\mathrm{m}}\left(\mathrm{PQH}_{2} / \mathrm{Q}_{\mathrm{B}}{ }^{-}\right)$, is higher than that of the first reduction, $E_{\mathrm{m}}\left(\mathrm{Q}_{\mathrm{B}}{ }^{-} / \mathrm{Q}_{\mathrm{B}}\right)$, and hence that $\mathrm{Q}_{\mathrm{B}}$ was electrochemically doubly reduced to $\mathrm{PQH}_{2}$ without forming singly reduced $\mathrm{Q}_{\mathrm{B}}{ }^{-}$as a major component. However, an ideal two-electron process 

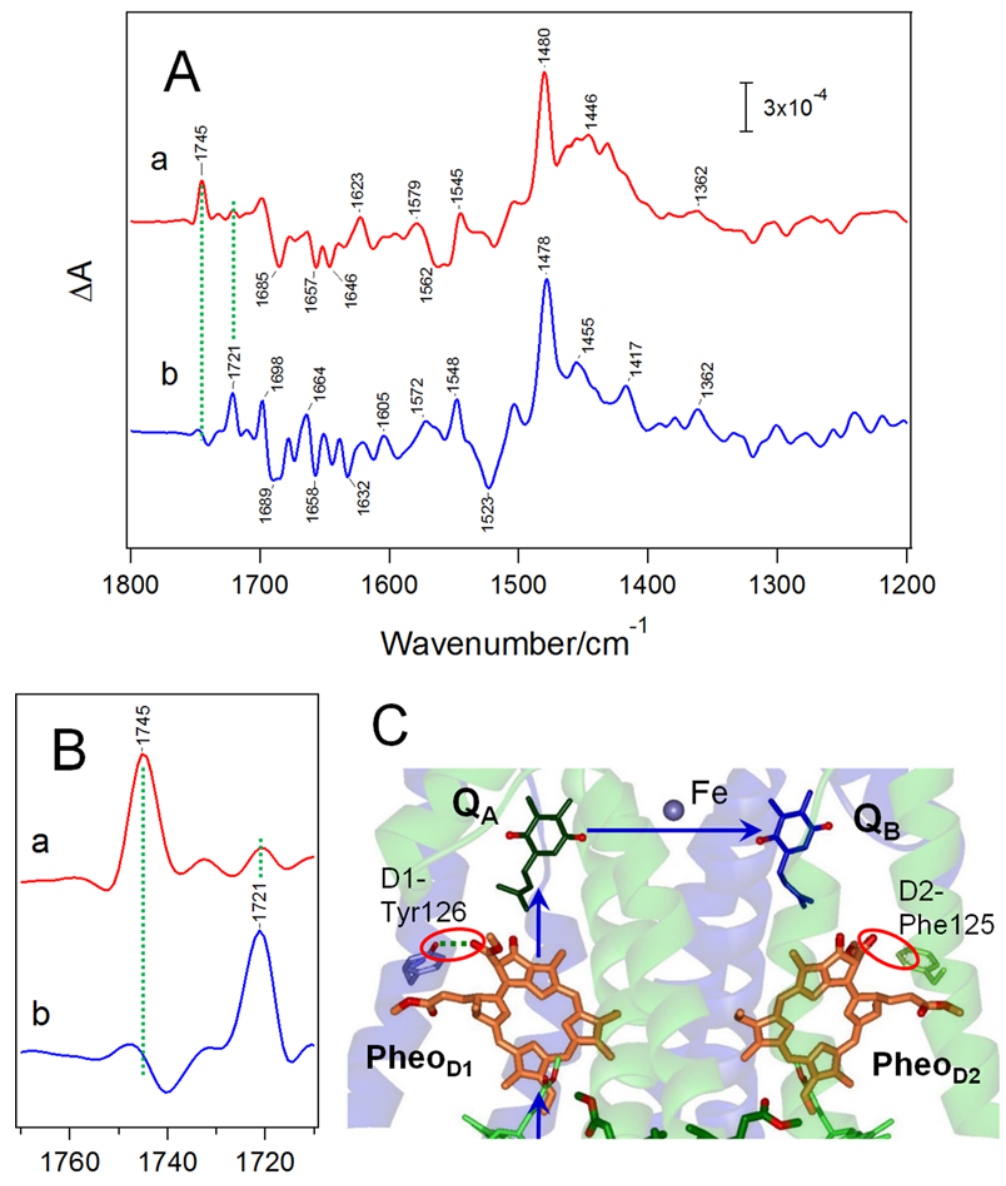

Wavenumber $/ \mathrm{cm}^{-1}$

Fig. 6. (A) Light-induced FTIR difference spectra upon single reduction of $\mathrm{Q}_{\mathrm{B}}$ (a) and $\mathrm{Q}_{\mathrm{A}}$ (b) of Mn-depleted PSII core complexes isolated from Thermosynechococcus elongatus. (B) Expanded spectra of the ester $\mathrm{C}=\mathrm{O}$ region of the $\mathrm{Q}_{\mathrm{B}}{ }^{-} / \mathrm{Q}_{\mathrm{B}}(\mathrm{a})$ and $\mathrm{Q}_{\mathrm{A}}{ }^{-} / \mathrm{Q}_{\mathrm{A}}$ (b) difference spectra. (C) Hydrogen-bond interactions of pheophytin electron acceptors located near $\mathrm{Q}_{\mathrm{A}}$ and $\mathrm{Q}_{\mathrm{B}}$ in PSII (PDB code: 3ARC [63]). Spectra in panels A and B are reproduced from Ref. [59].

with the slope value of $28 \mathrm{mV}$ is realized unless $E_{\mathrm{m}}\left(\mathrm{Q}_{\mathrm{B}}{ }^{-} / \mathrm{Q}_{\mathrm{B}}\right)$ is at least $180 \mathrm{mV}$ more negative than $E_{\mathrm{m}}\left(\mathrm{PQH}_{2} / \mathrm{Q}_{\mathrm{B}}{ }^{-}\right)$[2] (see also SI in [27]). Thermodynamic simulation of the experimental Nernst plots with $E_{\mathrm{m}}\left(\mathrm{Q}_{\mathrm{B}}{ }^{-} / \mathrm{Q}_{\mathrm{B}}\right)$ and $E_{\mathrm{m}}\left(\mathrm{PQH}_{2} / \mathrm{Q}_{\mathrm{B}}{ }^{-}\right)$as fitting parameters (Fig. $7 \mathrm{C}$ ) yielded the following $E_{\mathrm{m}}$ values at $\mathrm{pH}$ 6.5: $E_{\mathrm{m}}\left(\mathrm{Q}_{\mathrm{B}}{ }^{-} / \mathrm{Q}_{\mathrm{B}}\right)=+93 \pm 27 \mathrm{mV}$ and $E_{\mathrm{m}}\left(\mathrm{PQH}_{2} / \mathrm{Q}_{\mathrm{B}}{ }^{-}\right)=+213 \pm 36 \mathrm{mV}$ for intact PSII; $E_{\mathrm{m}}\left(\mathrm{Q}_{\mathrm{B}}{ }^{-} / \mathrm{Q}_{\mathrm{B}}\right)=+87 \pm 16 \mathrm{mV}$ and $E_{\mathrm{m}}\left(\mathrm{PQH}_{2} / \mathrm{Q}_{\mathrm{B}}{ }^{-}\right)=+157 \pm 36 \mathrm{mV}$ for Mn-depleted PSII. These are the $E_{\mathrm{m}}$ values of $\mathrm{Q}_{\mathrm{B}}$ directly measured for the first time (to our knowledge).

By determining the $E_{\mathrm{m}}$ values of $\mathrm{Q}_{\mathrm{B}}$ in intact and Mn-deleted PSII samples, the mechanism of photoprotection when the $\mathrm{Mn}_{4} \mathrm{CaO}_{5}$ cluster is inactivated is now clear (Fig. 8). The $E_{\mathrm{m}}\left(\mathrm{Q}_{\mathrm{B}}{ }^{-} / \mathrm{Q}_{\mathrm{B}}\right)$ together with the reported $E_{\mathrm{m}}\left(\mathrm{Q}_{\mathrm{A}}{ }^{-} / \mathrm{Q}_{\mathrm{A}}\right)$ (approximately $-100 \mathrm{mV}[1,24,26,30,31,56,57]$ ) provided the $\Delta E_{\mathrm{m}}$ between $\mathrm{Q}_{\mathrm{A}}$ and $\mathrm{Q}_{\mathrm{B}}$ as approximately $190 \mathrm{mV}$ in intact PSII [27]. Mn depletion induces a negative shift of $E_{\mathrm{m}}\left(\mathrm{Q}_{\mathrm{B}}{ }^{-} / \mathrm{Q}_{\mathrm{B}}\right)$ by only $6 \mathrm{mV}$ [27], which is in sharp contrast to a large positive shift $(\sim+150 \mathrm{mV})$ of $E_{\mathrm{m}}\left(\mathrm{Q}_{\mathrm{A}}{ }^{-} / \mathrm{Q}_{\mathrm{A}}\right)$ by the same treatment $[1,24,26,30,31,56,57]$. Thus, $\Delta E_{\mathrm{m}} \sim 190 \mathrm{mV}$ for the first reduction of $\mathrm{Q}_{\mathrm{B}}$ in intact PSII decreases to $\sim 40 \mathrm{mV}$ (Fig. 8B). This large decrease in $\Delta E_{\mathrm{m}}$ plays a significant 

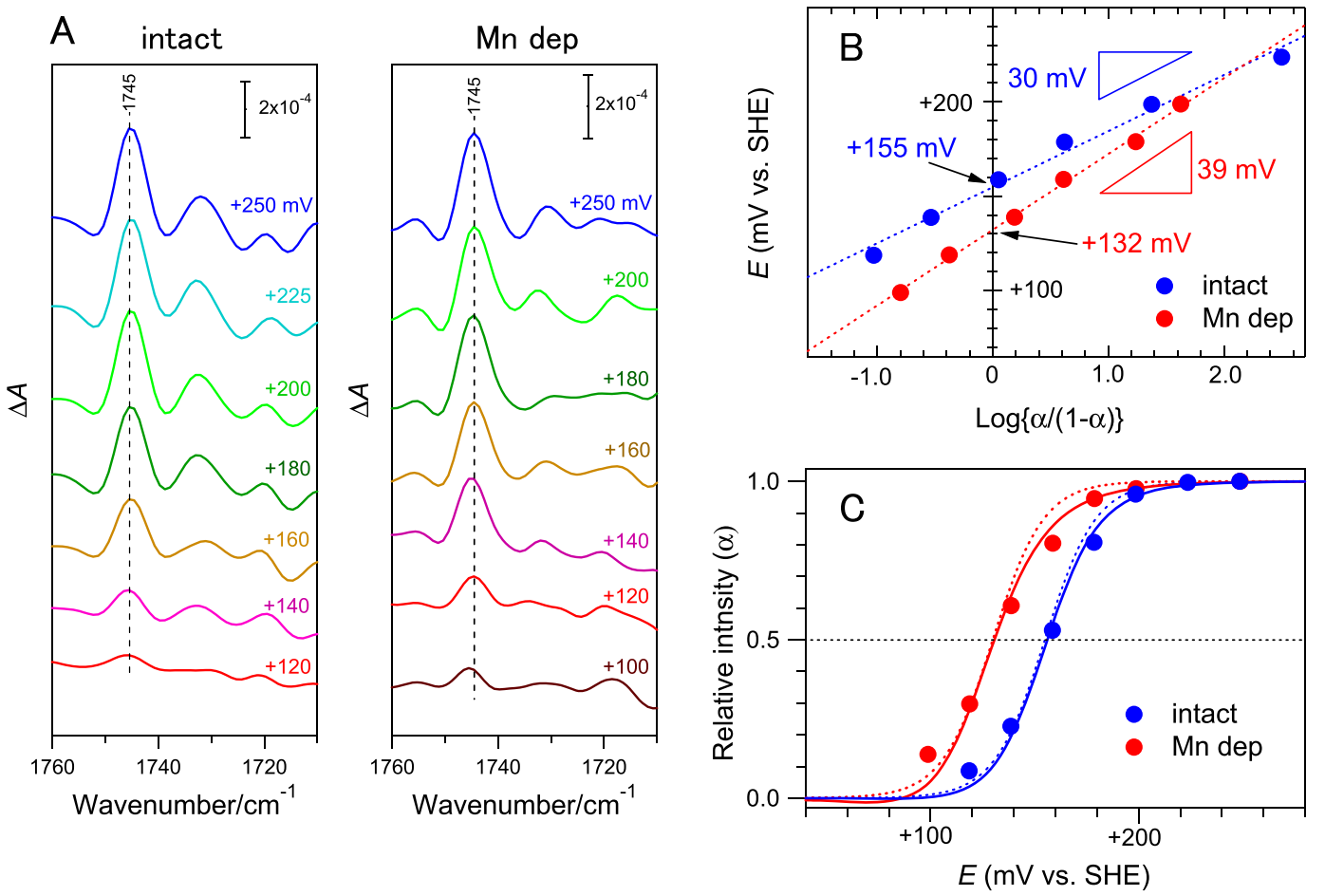

Fig. 7. (A) The $1745 \mathrm{~cm}^{-1}$ band specific to $\mathrm{Q}_{\mathrm{B}}{ }^{-} / \mathrm{Q}_{\mathrm{B}}$ at a series of the electrode potentials for the intact (left panel) and Mn-depleted (right panel) PSII core complexes from T. elongatus. The contribution of the $\mathrm{Q}_{\mathrm{A}}^{-} / \mathrm{Q}_{\mathrm{A}}$ signal (typically at $1721 \mathrm{~cm}^{-1}$ ) was eliminated by subtraction of the $\mathrm{Q}_{\mathrm{A}}{ }^{-} / \mathrm{Q}_{\mathrm{A}}$ difference spectrum measured at $+50 \mathrm{mV}$ from each spectrum. (B) Semi-logarithmic Nernst plots of the redox reactions of $\mathrm{Q}_{\mathrm{B}}$ in the intact (blue circles) and Mn-depleted (red circles) PSII core complexes. $\alpha$ indicates the intensity ratio of the $1745 \mathrm{~cm}^{-1}$ peak at each electrode potential relative to the intensity at $+250 \mathrm{mV}$, at which $\mathrm{Q}_{\mathrm{B}}$ is fully oxidized. The regression lines (dashed lines) with slopes and intercepts are also shown. (C) Fitting of the experimental intensity ratios $(\alpha)$ with theoretical Nernst curves for the intact (blue lines) and Mn-depleted (red lines) PSII samples. Dashed lines reveal the theoretical curves of two-electron reactions with $E_{\mathrm{m}}$ of +155 (intact) and +132 (Mn-depleted) $\mathrm{mV}$, while solid lines reveal the simulated curves with $E_{\mathrm{m}}$ values of the first and second reduction of $\mathrm{Q}_{\mathrm{B}}$ as fitting parameters: $E_{\mathrm{m}}\left(\mathrm{Q}_{\mathrm{B}}{ }^{-} / \mathrm{Q}_{\mathrm{B}}\right)=+93 \mathrm{mV}$ and $E_{\mathrm{m}}\left(\mathrm{PQH}_{2} / \mathrm{Q}_{\mathrm{B}}{ }^{-}\right)=+213 \mathrm{mV}$ for intact PSII, and $E_{\mathrm{m}}\left(\mathrm{Q}_{\mathrm{B}}{ }^{-} / \mathrm{Q}_{\mathrm{B}}\right)=+87 \mathrm{mV}$ and $E_{\mathrm{m}}\left(\mathrm{PQH}_{2} / \mathrm{Q}_{\mathrm{B}}{ }^{-}\right)=+157 \mathrm{mV}$ for Mn-depleted PSII. Reprinted from Ref. [27].

role in photoprotection. The $\Delta E_{\mathrm{m}}$ decrease accelerates backward electron transfer from $\mathrm{Q}_{\mathrm{B}}{ }^{-}$to $\mathrm{Q}_{\mathrm{A}}$ to facilitate direct charge recombination of $\mathrm{Q}_{\mathrm{A}}{ }^{-}$with $\mathrm{P} 680^{+}$, preventing oxidative damage by $\mathrm{P} 680^{+}$ [10,54]. In addition, the large positive shift of $E_{\mathrm{m}}\left(\mathrm{Q}_{\mathrm{A}}{ }^{-} / \mathrm{Q}_{\mathrm{A}}\right)$ increases $\Delta E_{\mathrm{m}}$ between $\mathrm{Pheo}_{\mathrm{D} 1}$ and $\mathrm{Q}_{\mathrm{A}}$ and hence prevents charge recombination via $\mathrm{PheO}_{\mathrm{D} 1}{ }^{-}$, which otherwise leads to generation of harmful singlet oxygen via a chlorophyll triplet state $[10,26,32,54,65,66]$.

\section{Concluding remarks}

The combined method of thin-layer electrochemistry and light-induced FTIR difference spectroscopy was applied to study the redox properties of the non-heme iron and the terminal quinone $\mathrm{Q}_{B}$ on the electron-acceptor side of PSII. In particular, the FTIR signal specific to $\mathrm{Q}_{\mathrm{B}}$ reduction enabled the first direct measurement of the $E_{\mathrm{m}}$ of $\mathrm{Q}_{\mathrm{B}}$ [27], which has not been achieved by other spectroscopic methods. This success demonstrated that this combined FTIR method is a very powerful tool to investigate redox 

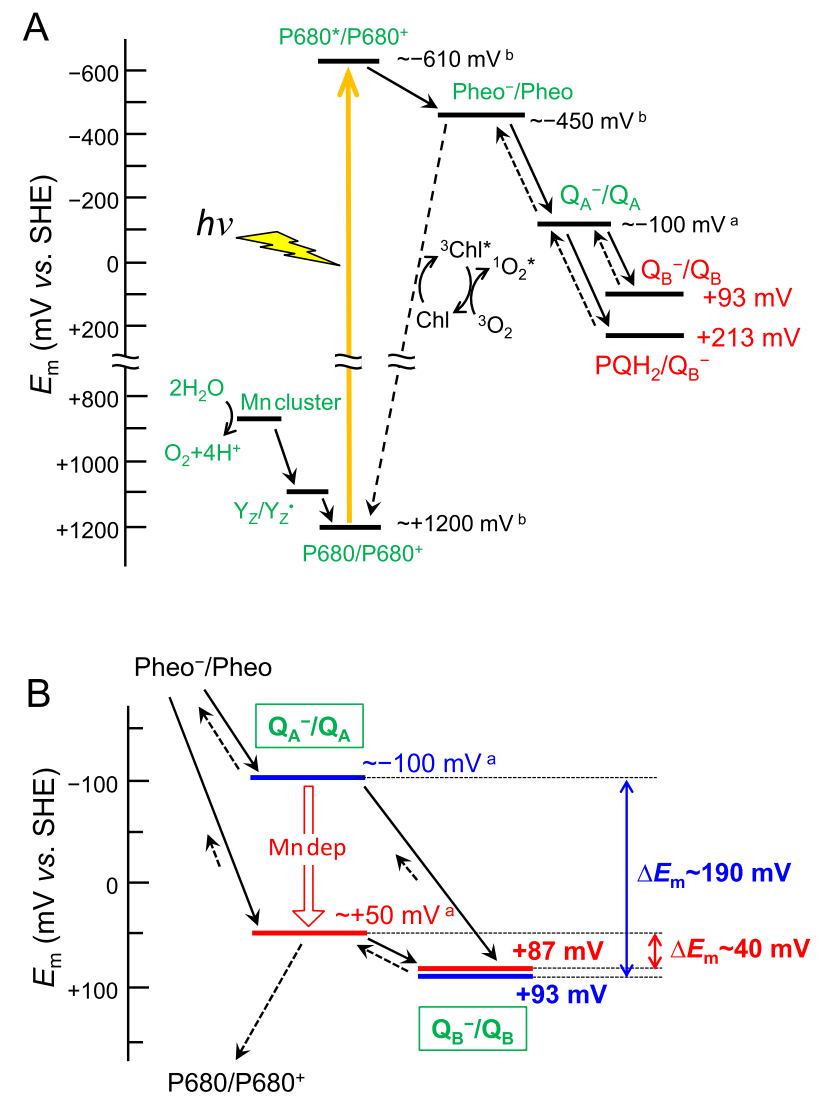

Fig. 8. (A) Diagram of the redox potentials of the electron transfer components in PSII. (B) The effect of Mn depletion on the redox potentials of single reduction of $\mathrm{Q}_{\mathrm{A}}$ and $\mathrm{Q}_{\mathrm{B}}$. Solid and dashed black arrows indicate forward and backward electron transfer, respectively. The redox potential levels of intact and Mn-depleted PSII are expressed by blue and red bars, respectively,

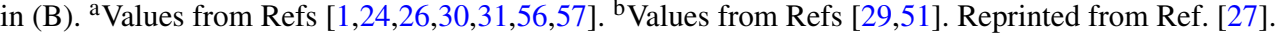

reactions in photosensitive proteins. The determination of $E_{\mathrm{m}}\left(\mathrm{Q}_{\mathrm{B}}{ }^{-} / \mathrm{Q}_{\mathrm{B}}\right)$ and its shift upon depletion of the $\mathrm{Mn}_{4} \mathrm{CaO}_{5}$ cluster showed a clear view of electron transfer regulation in PSII (Fig. 8), which functions as a photoprotection mechanism when the $\mathrm{Mn}_{4} \mathrm{CaO}_{5}$ cluster is impaired. Another merit of FTIR spectroelectrochemistry is that structural information can be obtained in addition to the redox property. It was shown that Mn depletion affected the protonation states of amino acid residues near the non-heme iron, which may cause the shift of the $E_{\mathrm{m}}\left(\mathrm{Fe}^{2+} / \mathrm{Fe}^{3+}\right)$ [28].

Although the mechanism of electron transfer regulation in PSII was clarified by determination of the $E_{\mathrm{m}}$ of $\mathrm{Q}_{\mathrm{B}}$, the molecular mechanism of the long-range interaction between the $\mathrm{Mn}_{4} \mathrm{CaO}_{5}$ cluster on the electron-donor side and the quinone molecules on the electron-acceptor side remains unclear. First it was predicted that the structural change by Mn depletion is transferred to the $\mathrm{Q}_{\mathrm{B}}$ site via the membrane-spanning helices of the $\mathrm{D} 1$ protein and then to $\mathrm{Q}_{\mathrm{A}}$ via the non-heme iron bridge (Fig. 1) [10], resulting in a large $E_{\mathrm{m}}\left(\mathrm{Q}_{\mathrm{A}}{ }^{-} / \mathrm{Q}_{\mathrm{A}}\right)$ shift by $+150 \mathrm{mV}$. However, this prediction was not consistent with the observations of relatively small shifts of $E_{\mathrm{m}}\left(\mathrm{Q}_{\mathrm{B}}{ }^{-} / \mathrm{Q}_{\mathrm{B}}\right)$ and $E_{\mathrm{m}}\left(\mathrm{Fe}^{2+} / \mathrm{Fe}^{3+}\right)(+6$ and $+18 \mathrm{mV}$, respectively) upon Mn depletion (Figs 4 and 7) [28]. Thus, there could be other pathways of long-range interaction to affect $E_{\mathrm{m}}\left(\mathrm{Q}_{\mathrm{A}}{ }^{-} / \mathrm{Q}_{\mathrm{A}}\right)$ without using the $\alpha$-helices of the D1 protein. Meanwhile, it was suggested that the $\mathrm{p} K_{\mathrm{a}}$ of a Glu residue near the non-heme iron is changed upon Mn depletion [28]. It is 
possible that such a Glu residue together with other several Glu residues located on the stromal side of PSII electrostatically controls the $E_{\mathrm{m}}\left(\mathrm{Q}_{\mathrm{A}}{ }^{-} / \mathrm{Q}_{\mathrm{A}}\right)$ by changing the protonation state. Further FTIR studies using spectroelectrochemical and light-induced difference methods in combination with site-directed mutagenesis at these amino acid residues are necessary to clarify the whole mechanism of electron transfer regulation and the donor- and acceptor-side communication in PSII.

\section{Acknowledgements}

This study was supported by JSPS KAKENHI (25410009 to Y.K., 24000018, 24107003, and 25291033 to T.N.).

\section{References}

[1] S.I. Allakhverdiev, T. Tsuchiya, K. Watabe, A. Kojima, D.A. Los, T. Tomo, V.V. Klimov and M. Mimuro, Redox potentials of primary electron acceptor quinone molecule $\left(\mathrm{Q}_{\mathrm{A}}\right)^{-}$and conserved energetics of photosystem II in cyanobacteria with chlorophyll $a$ and chlorophyll $d$, Proc. Natl. Acad. Sci. USA 108 (2011), 8054-8058.

[2] A.J. Bard and L.R. Faulkner, Electrochemical Methods, 2nd edn, Wiley, New York, 2001.

[3] M. Bauscher, E. Nabedryk, K. Bagley, J. Breton and W. Mäntele, Investigation of models for photosynthetic electron acceptors: Infrared spectroelectrochemistry of ubiquinone and its anions, FEBS Lett. 261 (1990), 191-195.

[4] C. Berthomieu and R. Hienerwadel, Iron coordination in photosystem II: Interaction between bicarbonate and the $Q_{B}$ pocket studied by Fourier transform infrared spectroscopy, Biochemistry 40 (2001), 4044-4052.

[5] C. Berthomieu and R. Hienerwadel, Fourier transform infrared (FTIR) spectroscopy, Photosynth. Res. 101 (2009), 157170.

[6] S.P. Best, Spectroelectrochemistry of hydrogenase enzymes and related compounds, Coord. Chem. Rev. 249 (2005), 15361554.

[7] S.P. Best, S.J. Borg and K.A. Vincent, Infrared spectroelectrochemistry, in: Spectroelectrochemistry, W. Klaim and A. Klein, eds, Royal Society of Chemistry, Cambridge, UK, 2008, pp. 1-30.

[8] J. Bowes, A.R. Crofts and S. Itoh, A high potential acceptor for photosystem II, Biochim. Biophys. Acta 547 (1979), $320-335$

[9] J. Cao and Govindjee, Chlorophyll $a$ fluorescence transient as an indicator of active and inactive photosystem II in thylakoid membranes, Biochim. Biophys. Acta 1015 (1990), 180-188.

[10] T. Cardona, A. Sedoud, N. Cox and A.W. Rutherford, Charge separation in photosystem II: A comparative and evolutionary overview, Biochim. Biophys. Acta 1817 (2012), 26-43.

[11] H.-A. Chu, Fourier transform infrared difference spectroscopy for studying the molecular mechanism of photosynthetic water oxidation, Frontiers Plant Sci. 4 (2013), Article 146.

[12] A.R. Crofts and C.A. Wraight, The electrochemical domain of photosynthesis, Biochim. Biophys. Acta 726 (1983), 149185.

[13] R.J. Debus, Protein ligation of the photosynthetic oxygen-evolving center, Coord. Chem. Rev. 252 (2008), 244-258.

[14] R.J. Debus, FTIR studies of metal ligands, networks of hydrogen bonds, and water molecules near the active site $\mathrm{Mn}_{4} \mathrm{CaO}_{5}$ cluster in photosystem II, Biochim. Biophys. Acta 1847 (2015), 19-34.

[15] B.A. Diner, Dependence of the deactivation reactions of photosystem II on the redox state of plastoquinone pool a varied under anaerobic conditions: Equilibria on the acceptor side of photosystem II, Biochem. Biophys. Acta 460 (1977), 247258.

[16] B.A. Diner, V. Petrouleas and J.J. Wendoloski, The iron-quinone electron-acceptor complex of photosystem II, Physiol. Plant. 81 (1991), 423-436.

[17] P.L. Dutton, Redox potentiometry: Determination of midpoint potentials of oxidation-reduction components of biological electron-transfer systems, Methods Enzymol. 54 (1978), 411-435.

[18] K.N. Ferreira, T.M. Iverson, K. Maghlaoui, J. Barber and S. Iwata, Architecture of the photosynthetic oxygen-evolving center, Science 303 (2004), 1831-1838.

[19] C. Fufezan, C. Zhang, A. Krieger-Liszkay and A.W. Rutherford, Secondary quinone in photosystem II of Thermosynechococcus elongatus: Semiquinone-iron EPR signals and temperature dependence of electron transfer, Biochemistry $\mathbf{4 4}$ (2005), 12780-12789. 
[20] R.S.K.A. Gamage, S. Umapathy and A.J. McQuillan, OTTLE cell study of the UV-visible and FTIR spectroelectrochemistry of the radical anion and dianion of 1,4-benzoquinone in DMSO solutions, J. Electroanal. Chem. 284 (1990), $229-235$.

[21] A. Guskov, J. Kern, A. Gabdulkhakov, M. Broser, A. Zouni and W. Saenger, Cyanobacterial photosystem II at 2.9-^ resolution and the role of quinones, lipids, channels and chloride, Nat. Struct. Mol. Biol. 16 (2009), 334-342.

[22] R. Hienerwadel and C. Berthomieu, Bicarbonate binding to the non-heme iron of photosystem II investigated by Fourier transform infrared difference spectroscopy and ${ }^{13}$ C-labeled bicarbonate, Biochemistry 34 (1995), 16288-16297.

[23] W. Hillier and J. Messinger, Mechanism of photosynthetic oxygen production, in: Photosystem II: The Light-Driven Water: Plastoquinone Oxidoreductase, T. Wydrzynski and K. Satoh, eds, Springer, Dordrecht, The Netherlands, 2005, pp. 567-608.

[24] K. Ido, C.M. Gross, F. Guerrero, A. Sedoud, T.-L. Lai, K. Ifuku, A.W. Rutherford and A. Krieger-Liszkay, High and low potential forms of the $\mathrm{Q}_{\mathrm{A}}$ quinone electron acceptor in photosystem II of Thermosynechococcus elongatus and spinach, J. Photochem. Photobiol. B 104 (2011), 154-157.

[25] I. Ikegami and S. Katoh, Studies on chlorophyll fluorescence in chloroplasts II. Effect of ferricyanide on the induction of fluorescence in the presence of 3-(3,4-dichlorophynyl)-1,1-dimethylurea, Plant Cell Phys. 14 (1973), 829-836.

[26] G.N. Johnson, A.W. Rutherford and A. Krieger, A change in the midpoint potential of the quinone $Q_{A}$ in photosystem II associated with photoactivation of oxygen evolution, Biochim. Biophys. Acta 1229 (1995), 202-207.

[27] Y. Kato, R. Nagao and T. Noguchi, Redox potential of the terminal quinone electron acceptor $Q_{B}$ in photosystem II reveals the mechanism of electron transfer regulation, Proc. Natl. Acad. Sci. USA 113 (2016), 620-625.

[28] Y. Kato and T. Noguchi, Long-range interaction between the $\mathrm{Mn}_{4} \mathrm{CaO}_{5}$ cluster and the non-heme iron center in photosystem II as revealed by FTIR spectroelectrochemistry, Biochemistry 53 (2014), 4914-4923.

[29] Y. Kato, M. Sugiura, A. Oda and T. Watanabe, Spectroelectrochemical determination of the redox potential of pheophytin $a$, the primary electron acceptor in photosystem II, Proc. Natl. Acad. Sci. USA 106 (2009), 17365-17370.

[30] A. Krieger, A.W. Rutherford and G.N. Johnson, On the determination of redox midpoint potential of the primary quinone electron acceptor, $Q_{A}$, in photosystem II, Biochim. Biophys. Acta 1229 (1995), 193-201.

[31] A. Krieger and E. Weis, Energy-dependent of chlorophyll- $a$-fluorescence: The involvement of proton-calcium exchange at photosystem 2, Photosynthetica 27 (1992), 89-98.

[32] A. Krieger-Liszkay, C. Fufezan and A. Trebst, Singlet oxygen production in photosystem II and related protection mechanism, Photosynth. Res. 98 (2008), 551-564.

[33] D. Lazár, Chlorophyll a fluorescence induction, Biochim. Biophys. Acta 1412 (1999), 1-28.

[34] W.G. Mäntele, A.M. Wollenweber, E. Nabedryk and J. Breton, Infrared spectroelectrochemistry of bacteriochlorophylls and bacteriopheophytins: Implications for the binding of the pigments in the reaction center from photosynthetic bacteria, Proc. Natl. Acad. Sci. USA 85 (1988), 8468-8472.

[35] F. Melin and P. Hellwig, Recent advances in the electrochemistry and spectroelectrochemistry of membrane proteins, Biol. Chem. 394 (2013), 593-609.

[36] J. Messinger, T. Noguchi and J. Yano, Photosynthetic $\mathrm{O}_{2}$ evolution, in: Molecular Solar Fuels, T. Wydrzynski and W. Hillier, eds, Royal Society of Chemistry, Cambridge, UK, 2011, Chapter 7.

[37] D. Moss, E. Nabedryk, J. Breton and W. Mäntele, Redox-linked confromational changes in proteins detected by a combination of infrared spectroscopy and protein electrochemistry, Eur. J. Biochem. 187 (1990), 565-572.

[38] F. Müh, C. Glöckner, J. Hellomich and A. Zouni, Light-induced quinone reduction in photosystem II, Biochim. Biophys. Acta 1817 (2012), 44-65.

[39] T. Noguchi, Light-induced FTIR difference spectroscopy as a powerful tool toward understanding the molecular mechanism of photosynthetic oxygen evolution, Photosynth. Res. 91 (2007), 59-69.

[40] T. Noguchi, Fourier transform infrared analysis of the photosynthetic oxygen-evolving center, Coord. Chem. Rev. 252 (2008), 336-346.

[41] T. Noguchi, Monitoring the reactions of photosynthetic water oxidation using infrared spectroscopy, Biomed. Spectrosc. Imaging 2 (2013), 115-128.

[42] T. Noguchi, Fourier transform infrared difference and time-resolved infrared detection of the electron and proton transfer dynamics in photosynthetic water oxidation, Biochim. Biophys. Acta 1847 (2015), 35-45.

[43] T. Noguchi and C. Berthomieu, Molecular analysis by vibrational spectroscopy, in: Photosystem II: The Light-Driven Water: Plastoquinone Oxidoreductase, T. Wydrzynski and K. Satoh, eds, Springer, Dordrecht, The Netherlands, 2005, pp. 367-387.

[44] T. Noguchi and Y. Inoue, Identification of Fourier transform infrared signals from the non-heme iron in photosystem II, J. Biochem. 118 (1995), 9-12.

[45] T. Noguchi, T. Ono and Y. Inoue, Direct detection of a carboxylate bridge between $\mathrm{Mn}$ and $\mathrm{Ca}^{2+}$ in the photosynthetic oxygen-evolving center by means of Fourier transform infrared spectroscopy, Biochim. Biophys. Acta 1228 (1995), 189200 . 
[46] T. Noguchi and M. Sugiura, Analysis of flash-induced FTIR difference spectra of the S-state cycle in the photosynthetic water-oxidizing complex by uniform ${ }^{15} \mathrm{~N}$ and ${ }^{13} \mathrm{C}$ isotope labeling, Biochemistry 42 (2003), 6035-6042.

[47] G.C. Papageorgiou and Govindjee, Photosystem II fluorescence: Slow changes - Scaling from the past, J. Photochem. Photobiol. B Biol. 104 (2011), 258-270.

[48] V. Petrouleas and A.R. Crofts, The quinone iron acceptor complex, in: Photosystem II: The Light-Driven Water: Plastoquinone Oxidoreductase, T. Wydrzynski and K. Satoh, eds, Springer, Dordrecht, The Netherlands, 2005, pp. 177-206.

[49] V. Petrouleas and B.A. Diner, Identification of $\mathrm{Q}_{400}$, a high-potential electron acceptor of photosystem II, with the iron of the quinone-iron acceptor complex, Biochim. Biophys. Acta 849 (1986), 264-275.

[50] M.P.J. Pulles, H.J. van Gorkom and J.G. Willemsen, Absorbance changes due to charge-accumulating species in system 2 of photosynthesis, Biochim. Biophys. Acta 449 (1976), 536-540.

[51] F. Rappaport and B.A. Diner, Primary photochemistry and energetics leading to the oxidation of the (Mn) ${ }_{4} \mathrm{Ca}$ cluster and to the evolution of molecular oxygen in photosystem II, Coord. Chem. Rev. 252 (2008), 259-272.

[52] G. Renger, Photosynthetic water splitting: Apparatus and mechanism, in: Photosynthesis: Plastid Biology, Energy Conversion and Carbon Assimilation, J.J. Eaton-Rye, B.C. Tripathy and T.D. Sharkey, eds, Springer, Dordrecht, The Netherlands, 2012, Chapter 17.

[53] H.H. Robinson and A.R. Crofts, Kinetics of the oxidation-reduction reactions of the photosystem II quinone acceptor complex, and the pathway for deactivation, FEBS Lett. 153 (1983), 221-226.

[54] A.W. Rutherford, A. Osyczka and F. Rappaport, Back-reactions, short-circuits, leaks and other energy wasteful reactions in biological electron transfer: Redox tuning to survive life in $\mathrm{O}_{2}$, FEBS Lett. 586 (2012), 603-616.

[55] A. Sedoud, N. Cox, M. Sugiura, W. Lubitz, A. Boussac and A.W. Rutherford, Semiquinone-iron complex of photosystem II: EPR signals assigned to the low-field edge of the ground state doublet of $\mathrm{Q}_{\mathrm{A}}{ }^{\bullet-} \mathrm{Fe}^{2+}$ and $\mathrm{Q}_{\mathrm{B}}{ }^{\bullet-} \mathrm{Fe}^{2+}$, Biochemistry $\mathbf{5 0}$ (2011), 6012-6021.

[56] T. Shibamoto, Y. Kato, R. Nagao, T. Yamazaki, T. Tomo and T. Watanabe, Species-dependence of the redox potential of the primary quinone electron acceptor $\mathrm{Q}_{\mathrm{A}}$ in photosystem II verified by spectroelectrochemistry, FEBS Lett. 584 (2010), $1526-1530$.

[57] T. Shibamoto, Y. Kato, M. Sugiura and T. Watanabe, Redox potential of the primary plastoquinone electron acceptor $\mathrm{Q}_{\mathrm{A}}$ in photosystem II from Thermosynechococcus elongatus determined by spectroelectrochemistry, Biochemistry $\mathbf{4 8}$ (2009), $10682-10684$.

[58] T. Shibamoto, Y. Kato and T. Watanabe, Spectroelectrochemistry of cytochrome $b_{559}$ in the D1-D2-Cyt $b_{559}$ complex from spinach, FEBS Lett. 582 (2008), 1490-1494.

[59] H. Suzuki, M. Nagasaka, M. Sugiura and T. Noguchi, Fourier transform infrared spectrum of the secondary quinone electron acceptor $\mathrm{Q}_{\mathrm{B}}$ in photosystem II, Biochemistry 44 (2005), 11323-11328.

[60] R. Takahashi, A. Boussac, M. Sugiura and T. Noguchi, Structural coupling of a tyrosine side chain with the non-heme iron center in photosystem II as revealed by light-induced Fourier transform infrared difference spectroscopy, Biochemistry 48 (2009), 8994-9001.

[61] R. Takahashi, K. Hasegawa, A. Takano and T. Noguchi, Structures and binding sites of phenolic herbicides in the $\mathrm{Q}_{\mathrm{B}}$ pocket of photosystem II, Biochemistry 49 (2010), 5445-5454.

[62] I. Taniguchi, K. Toyosawa, H. Yamaguchi and K. Yasukouchi, Voltammetric response of horse heat cytochrome $c$ at a gold electrode in the presence of sulfur bridged bipyridines, J. Electroanal. Chem. 140 (1982), 187-193.

[63] Y. Umena, K. Kawakami, J.-R. Shen and N. Kamiya, Crystal structure of oxygen-evolving photosystem II at a resolution of $1.9 \AA$ A Nature 473 (2011), 55-60.

[64] H.J. van Gorkom, Identification of reduced primary electron-acceptor of photosystem II as a bound semiquinone anion, Biochim. Biophys. Acta 347 (1974), 439-442.

[65] I. Vass, Role of charge recombination processes in photodamage and photoprotection of the photosystem II complex, Physiol. Plant 142 (2011), 6-16.

[66] I. Vass and K. Cser, Janus-faced charge recombinations in photosystem II photoinhibition, Trends Plant Sci. 14 (2009), 200-205.

[67] T. Wydrzynski and K. Satoh (eds), Photosystem II: The Light-Driven Water: Plastoquinone Oxidoreductase, Springer, Dordrecht, The Netherlands, 2005. 